\title{
Passageiros da noite: do trabalho para a EJA. Itinerários pelo direito a uma vida justa
}

\author{
Edna Maria de Oliveira Ferreira/(D) \\ César Costa Vitorino"(D)
}

\begin{abstract}
ARROYO, M. G. Passageiros da noite: do trabalho para a EJA. Itinerários pelo direito a uma vida justa. Petrópolis: Vozes, 2017. 294p.
\end{abstract}

Miguel Gonzáles Arroyo, com muita sensibilidade, nos presenteia com a obra Passageiros da noite: do trabalho para a EJA, publicada pela editora Vozes em 2017. A Educação de Jovens e Adultos (EJA) tem particularidades como qualquer modalidade de ensino, e uma delas diz respeito às características de seu público-alvo: pessoas que vivem em condições precárias, em sua maioria são desempregadas ou subempregadas. A trajetória escolar desses sujeitos apresenta-se marcada por interrupções, quando foram excluídos da educação básica, não conseguindo acesso ou permanência no ensino regular em virtude de problemas de ordem social e econômica. Exatamente por ser o perfil de seu corpo discente tão único e complexo, vem a EJA merecendo cada vez mais atenção especial de pesquisadores.

Ao analisar o histórico da EJA no Brasil, percebem-se avanços tanto de ordem conceitual quanto organizacional: a EJA não tem mais o caráter supletivo e compensatório que perdurou por muito tempo. É vista como um processo educacional voltado a atender jovens e adultos que não frequentaram a escola em idade certa, trazendo uma visão equalizadora, de compromisso com a qualidade social da formação e com vistas à inclusão.

Avanços aconteceram também na criação de políticas públicas que valorizem iniciativas para se chegar a um currículo próximo das reais necessidades do seu público-alvo, na busca por metodologias de trabalho para grupos de alunos heterogêneos, além da conquista de estrutura organizacional capaz de atender a essas exigências, entre outros. Nesse contexto, é importante lembrar que a concepção de EJA leva em consideração o currículo e toda prática pedagógica. E podemos

'Instituto Federal de Educação, Ciência e Tecnologia Baiano, Senhor do Bonfim, BA, Brasil.

"Universidade do Estado da Bahia, Salvador, BA, Brasil. 
dizer que currículo e prática pedagógica estão amparados em uma compreensão de educação democrática, em uma visão de mundo que indica determinado perfil do sujeito para quem se pensa o currículo.

Outro aspecto importante e que provavelmente promoveu mais avanços foi o acolhimento da EJA pela Lei de Diretrizes e Bases da Educação Nacional (LDB/1996), o que contribuiu para que essa modalidade de ensino adquirisse relativa importância e direito social. Daí surgirem estudos e pesquisas voltados para essa modelo específico de ensino, além da promoção de eventos em que profissionais atuando na EJA discutem, refletem, vivenciam e trocam experiências sobre os problemas mais evidentes nesse processo de escolarização.

Passageiros da noite apresenta vinte e três capítulos e aborda de forma bastante sensível e postura reflexiva a ausência de identidade que acompanha cada adolescente-criança ou jovem-adulto trabalhador que se dirige à EJA todas as noites, carregando esperança e confiando na promessa de melhorias pessoais, na conquista de uma vida mais justa, mais digna e mais humana, após concluir seus estudos. Mas isso acontece de fato?

Miguel Arroyo, professor titular emérito da Faculdade de Educação da Universidade Federal de Minas Gerais (UFMG), reporta-se às ideias propostas no livro Pedagogia do oprimido, de Paulo Freire, para em tom quase apelativo, ou pelo menos de indignação, sensibilizar o leitor a perceber que há um grande distanciamento entre esses sujeitos de (não) direitos, jovens-adultos ou adolescentes-crianças, e a possibilidade de os mestres-educadores garantirem o entendimento de eles se compreenderem como vítimas de desigualdades e terem atitude de resistência diante das injustiças sofridas.

No livro, esse distanciamento é marcado por questionamentos sobre o olhar com que os alunos da EJA percebem seus professores-educadores e de como exigem ser enxergados por eles, e sobre como os educadores veem os percursos e itinerários escolares (ou de vida!) feitos pelos alunos trabalhadores em busca de igualdade e justiça. $\mathrm{O}$ autor prossegue com reflexões mais pertinentes à formação desses profissionais da educação, ou ainda quanto à função da pedagogia e da docência como arte ou ciência que defende o direito à formação humana. Enfim, fica claro que esses alunos pouco conhecem de si mesmos, procuram respostas às suas indagações na EJA, mas nem sempre encontram explicações confortantes; e essa ausência de identidade reforça o sentimento de desumanização do qual são vítimas.

Por meio de temas-texto, o leitor é convidado a ser também um "passageiro da noite" e embarcar nessa viagem meditativa, construída com o propósito de colaborar para transformar essa realidade do público frequentador da EJA: de vítimas da desumanização - e por isso "sujeitos de rebelião" - em “sujeitos de decisão"(Freire, 1987).

Logo na apresentação, fica evidente a desumanização, a falta de identidade própria tanto dos jovens-adultos trabalhadores quanto dos professores-educadores de EJA, que se reinventam no interior dessas escolas a cada dia. Nesse contexto, há uma busca, de ambas as partes, por reconhecimento da sociedade, dos formuladores de políticas públicas e da mídia, pelo respeito à ética profissional, por um currículo que não só garanta condições para que educadores e educandos entendam as relações sociais, de raça, de gênero, de trabalho, como também pautado em saberes e em valores que sejam reflexo dessa identidade e, assim, fortaleça neles a resistência em 
prol de uma emancipação. Além da apresentação, há outros dez temas-texto dos quais se originam os demais capítulos.

Os primeiros capítulos se propõem, entre outros temas, a caracterizar quem é esse passageiro da noite, quais são suas passagens, seus itinerários, de que trabalho instável vem, de que forma esse trabalho está (?) contemplado na agenda pedagógica da EJA. Nos capítulos seguintes, Arroyo aborda questões mais ligadas aos sujeitos coletivos de direitos que são os jovens e adultos de EJA, enfatizando o direito a uma vida justa, ao conhecimento, à cultura, à diversidade, à memória e à sua história, que frequentemente lhes é negada.

Mais para o final da obra, nos seis últimos capítulos, o autor sugere uma aproximação entre estudos das identidades juvenis defendendo que estes sejam levados para o interior das escolas de EJA, no intuito de garantir aos alunos um conhecimento escolar libertador e capaz de lhes permitir "saberem-se vivos" e com direito à vida.

O capítulo que fecha o livro o faz com chave de ouro, pois, ao propor uma pedagogia dos corpos, Arroyo coloca o leitor diante de reflexões profundas sobre uma das dicotomias vigentes nas escolas "corpo/mente", em que o jovem ou adulto é visto apenas como "mente incorpórea" (p. 274). Ou seja, a preocupação da escola limita-se à mente do educando, ignorando sua corporeidade, $\mathrm{a}(\mathrm{s})$ linguagem(ens) de seu corpo. Daí, talvez, a crise de identidade individual e de seus coletivos, uma vez que "o encontro entre o sujeito e ele mesmo pode vir pelo corpo" ( p. 283).

Em relação à forma de articular as ideias nos textos que compõem os capítulos, é interessante observar que o autor o faz com maestria, criando neologismos com a derivação e a composição de palavras como opção segura para aproximar o leitor da sensibilidade que o move ao escrever. Servem de exemplos os termos "humanos-desumanos" (p.12), "jovens-adultos-adolescentes-crianças" (p. 10), "percursos de segregação-reação" (p. 27), que assim construídos adquirem nova semântica no contexto de uso, conferindo caráter apelativo à compreensão e interpretação do leitor, na tentativa de levá-los a conclusões mais próximas das ideias originais do autor.

Outra característica não menos interessante no estilo da escrita de Arroyo é a construção, principalmente nos capítulos iniciais, de frases curtas e rápidas. Às vezes compostas de uma só palavra, para enfatizar ideia já expressa e carregada de emoção, a exemplo de "Humana." (p. 7), "Por justiça." (p. 7), "Da história." (p. 210). Todas essas frases curtas reforçam ideias manifestadas e encaminham à compreensão leitora do interlocutor ao estado de alma de quem as escreve.

Ainda, o livro traz sugestões de letras de músicas que servem de mote para a discussão dos temas-texto, tanto para a formação dos mestres quanto para a dos educandos. Os alunos se reconhecem nas letras, que trazem suas angústias, inseguranças, dúvidas e anseios. Então as composições sugeridas tornam-se material saudável nas aulas de EJA, como acesso à cultura e à criatividade artística que deve ser garantida pelo Estado, argumenta o autor.

Essa obra torna-se forte aliada dos pesquisadores e dos que vivem esse contexto na educação. De leitura agradável, flui muito bem. Todo profissional de EJA ou responsáveis em formular políticas públicas para essa modalidade devem buscar essa experiência de leitura. Devem deixar-se embriagar pelas reflexões, prestarem-se às análises que a 
leitura da obra provoca. Principalmente em tempos sombrios como os que agora vivemos, quando mudanças no ensino médio ou em outras modalidades de ensino vêm se impondo como necessárias, sem terem sido discutidas a contento pela sociedade, que vive um alheamento total, em um retrocesso ímpar. Ou ainda com a proposta perversa de reducionismo presente na ideia de submissão da formação inicial e continuada de professores à Base Nacional Comum Curricular (Brasil, 2016).

Por fim, sem esgotar as análises possíveis sobre a obra, conclui-se lembrando que "a radiografia moral da sociedade [...] [e] da pedagogia" (p. 254) aponta para o distanciamento entre currículo, docência e formação cidadã. Faz-se necessário "o assombro ético-político [dos educadores]" (p. 257), assim como "o saborear do saber amargo-resistente de seu viver [do aluno]" (p. 257) como meio de alimentar novas perguntas, assim como interroga Freire (1987, p. 29): "Respondem, e suas respostas os levam a novas perguntas?".

\section{REFERÊNCIAS}

Arroyo, M. Passageiros da noite: do trabalho para a EJA. Itinerários pelo direito a uma vida justa. Petrópolis: Vozes, 2017.

Brasil. Lei n. 9.394, de 20 de dezembro de 1996. Estabelece as Diretrizes e Bases da Educação Nacional. Diário Oficial da União, Brasília, DF. Disponível em: <http://www. planalto.gov.br/ccivil 03/leis/L9394.htm>. Acesso em: 13 dez. 2018.

Brasil. Ministério da Educação. Secretaria da Educação Básica. Base Nacional Comum Curricular. Brasília, DF: 2016. Disponível em: <http://basenacionalcomum.mec.gov. br/\#/site/inicio>. Acesso em: jun. 2018.

Freire, P. Pedagogia do oprimido. 17. ed. Rio de Janeiro: Paz e Terra, 1987.

\section{SOBRE OS AUTORES}

Edna Maria de Oliveira Ferreira é mestre em educação agrícola pela Universidade Federal Rural do Rio de Janeiro (UFRRJ). Professora do Instituto Federal de Educação, Ciência e Tecnologia Baiano (IFBAIANO).

E-mail:edmaof@hotmail.com

CÉsar Costa Vitorino é doutor em letras pela Pontifícia Universidade Católica do Rio Grande do Sul (PUCRS). Professor da Universidade do Estado da Bahia (UNEB).

E-mail: vitorinoleitura66@gmail.com 